\title{
Meu Deus, dai-nos sempre poetas assim obscuros!
}

\section{Catarina Maia}

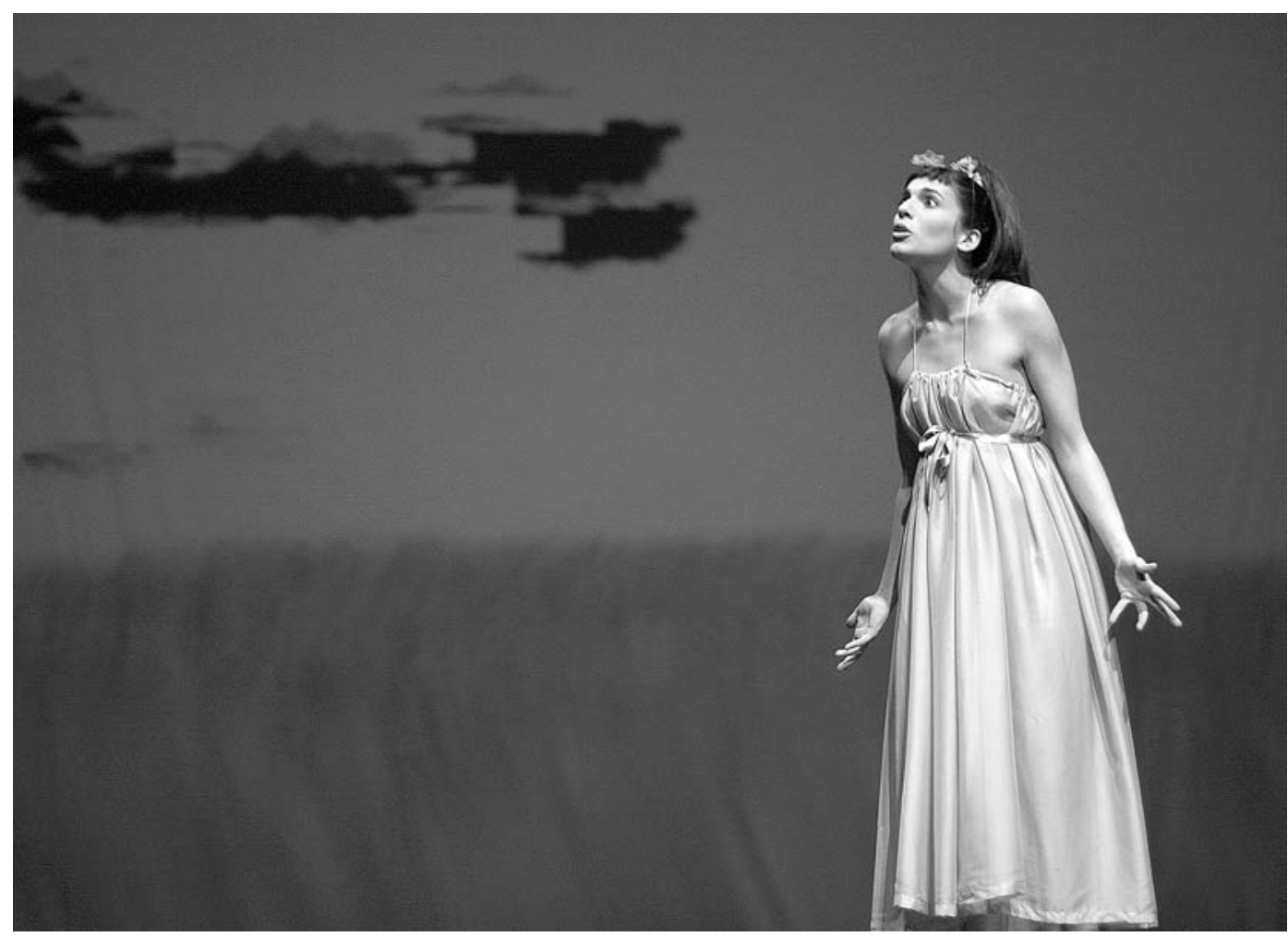

As portas da percepção, de William Blake, dir. Mário Montenegro, Marionet \&t TAGV, 2007 (Tanya Ruivo), fot. Francisca Moreira.

Titulo: Uma ilha na lua (An Island in the Moon, 1784). Autor: William Blake. Tradução: Manuel Portela. Direcção artística: José Geraldo. Figurinos: Isabel Pereira. Música original: Joaquim Pavão. Maestro: Carlos Marques. Interpretação musical: Orquestra Clássica do Centro. Cantores: Carla Pais (soprano) e Bruno Pereira (baixo). Desenho de luz: Celestino Gomes e José Geraldo. Interpretação: António Mortágua, Filipa Freitas, Helena Faria, José Geraldo e Pedro Malacas. Video: Filipa Freitas. Produção: Camaleão Associação Cultural e Teatro Académico de Gil Vicente. Local e data de estreia: Coimbra, Teatro Académico de Gil Vicente, 8 de Novembro de 2007.

Titulo: As portas da percepção (The Marriage of Heaven and Hell, 1790; The Book of Thel, 1789; The [First] Book of Urizen, 1794; The Song of Los, 1795; The Book of Ahania, 1795; Visions of the Daughters of Albion, 1793; Songs of Innocence and Experience, 1794). Autor: William Blake. Ideia, tradução e selecção de textos e imagens: Manuel Portela. Direcção artistica: Mário Montenegro. Assistência de direç̧ão e produção executiva: Alexandre. Cenografia e figurinos: Pedro Andrade. Sonoplastia: Rui Capitão. Desenho de luz: Rui Simão. Video: Laetítia Morais. Interpretação: Anabela Fernandes, Mário

Montenegro, Nuno Fareleira, Tanya Ruivo. Produção: Marionet e Teatro Académico de Gil Vicente. Local e data de estreia: Coimbra, Teatro Académico de Gil Vicente, 23 de Novembro de 2007.

Depois do ciclo dedicado a Beckett em 2006, o Teatro Académico de Gil Vicente (TAGV) escolheu o mês de Novembro de 2007 para celebrar William Blake (1757-1827). 0 ciclo de programação interdisciplinar Blake no TAGV mobilizou, durante todo o mês, exposições, música, rádio, teatro, multimédia, cinema e debates em torno e a partir da obra do autor inglês. Os 250 anos sobre o seu nascimento foram, nas palavras de Manuel Portela, director do TAGV e responsável pela concepção do ciclo, apenas um pretexto. 0 objectivo foi sobretudo, e em primeiro lugar, o de "celebrar e dar a conhecer de forma alargada a obra de um dos grandes artistas da humanidade". Esta intenção integrou portanto uma justíssima homenagem ao rememorar o mundo da figura obscura e visionária que foi William Blake. Este ciclo abriu com a exposição "7 visões de William Blake", integrando a participação de sete artistas (Pedro
Catarina Maia é

mestranda em Estudos Artísticos

(especialização em Estudos Cinematográficos) e monitora na Faculdade de Letras da Universidade de Coimbra. 


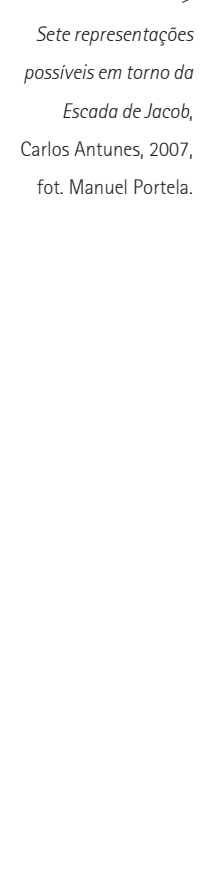

Estas imagens podem ser vistas no sitio do The William Blake Archive (http://www.blakearchive .org/blake/), um arquivo on linededicado à obra de

Blake. Começou a ser publicado em 1996 e tem continuado a expandir-se desde então, com novos materiais digitalizados $\mathrm{e}$ acrescentados periodicamente. Trata-se

de uma publicação do Instituto para Tecnologia

Avançada nas

Humanidades, da Universidade da Virgínia, organizado por Morris Eaves, Robert Essick e Joseph Viscomi. 0 arquivo

oferece ao ciberleitor

imagens digitalizadas das diferentes versões dos livros iluminados, além do

texto completo dos poemas, com informação textual e comentários múltiplos.

Manuel Portela, "Organizar o efémero 2", texto lido na abertura do ciclo, a 6 de Novembro de

2007, disponivel no blogue institucional: http://www.blogtagv.

blogspot.com.

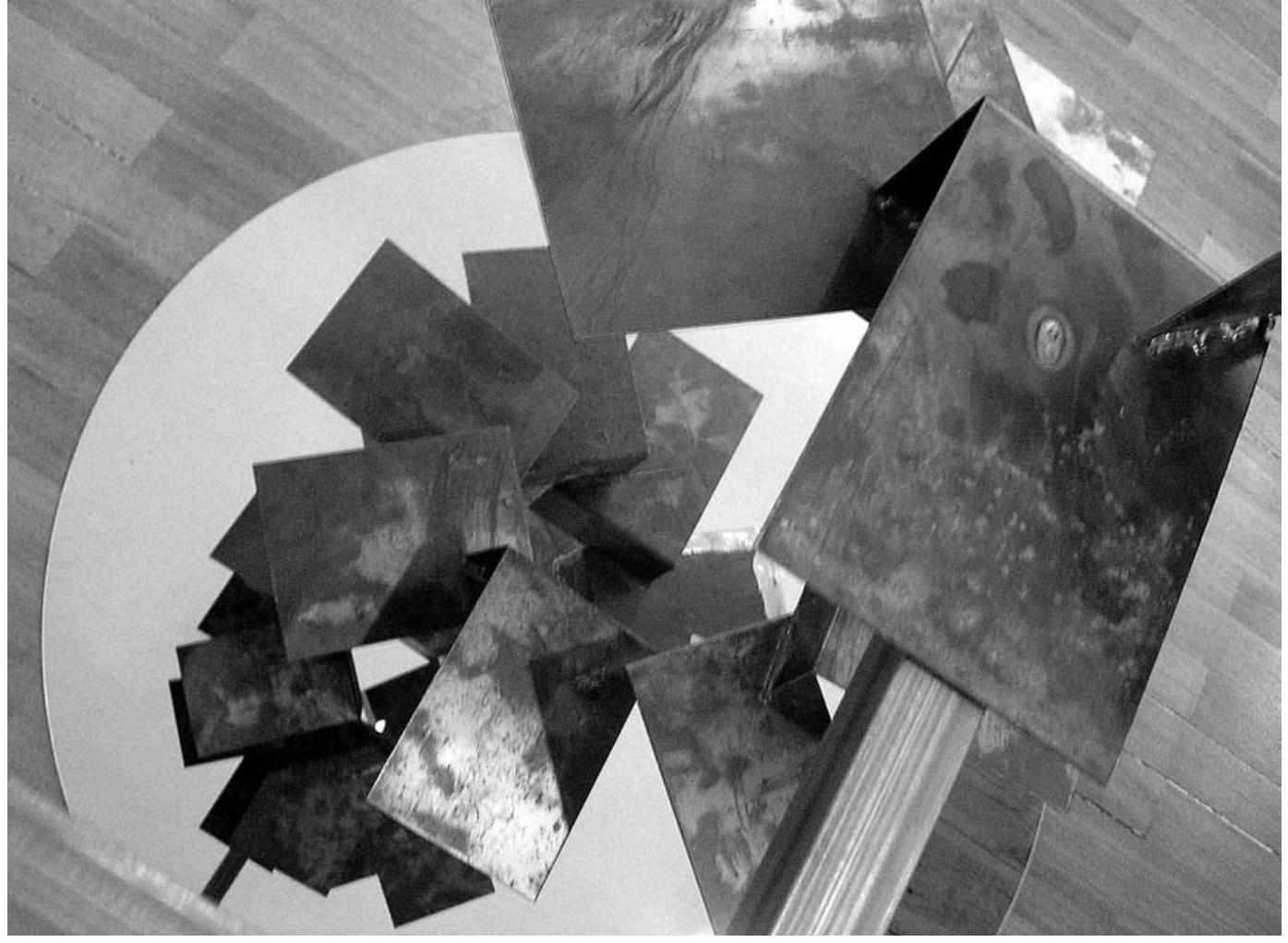

Pousada, Armando Azevedo, António Olaio, Emanuel Brás, Teresa Amaral, Gilberto Reis e o Atelier do Corvo) a quem foi proposta a criação de obras originais a partir de sete gravuras do poeta inglês. A exposição ocupou (literalmente) a sala do café-teatro durante toda a extensão do ciclo (6 a 28 de Novembro) com vários quadros, entre os quais destacaria "Watching Newton from Outerspace", um trabalho de António Olaio que propõe um jogo inteligente com a gravura original, Newton (1795, c.1805). A escolha de um novo enquadramento, como refere Olaio, valoriza a verticalidade ausente, "o espaço para onde este Newton não olha", e a destruição da pose perfeita e perfeitamente distante que Newton apresenta, conseguida com o uso de um modelo real (um aluno de Olaio), olhando directamente para nós. Desmonta-se assim a "farsa" da representação, transpondo o tema para a realidade imediata, ao mesmo tempo que o re-transcendentaliza, apostando no espaço sideral como ponto de vista. Para facilitar o confronto com as novas obras, foram expostas em paralelo reproduções miniaturizadas das sete gravuras seleccionadas.

Não sendo possível num tão curto espaço referir a totalidade das obras expostas, uma referência ainda para a instalação "Sete representações possíveis em torno da Escada de Jacob", produzida pelos artistas Carlos Antunes e Désirée Pedro (do Atelier Corvo), que chama

primeiramente a atenção do visitante pela sua dimensão: um enorme cedro invertido (copa no chão e tronco no ar) ocupava o centro da sala. Passada esta primeira impressão, a obra destaca-se pelos pormenores que pedem ao visitante que a observe de perto, que a investigue e que a contorne. É precisamente na miniatura, através do uso privilegiado de espelhos paralelos, que se cria a ideia de ligação infinita ao infinito - conceito presente na pintura de Blake, Jacob's Dream (c. 1805), referindo-se, como é evidente, ao sonho de Jacob (Génesis, 28: 12) onde este descreve uma escada que une a Terra ao Céu.
A inauguração desta exposição fez-se com a mesaredonda Blakeana 1: "Blake pintor", que contou com a presença dos artistas que realizaram obras a partir de gravuras e pinturas de William Blake para a exposição. Em simultâneo, na sala branca do TAGV, "William Blake: Livros iluminados", uma vídeoprojecção integral das páginas de dezassete livros iluminados (1788-1820) do autor inglês, ofereceu aos curiosos a oportunidade de observarem em grandes dimensões e com excelente definição uma enorme amostra da obra extraordinária de William Blake ${ }^{1}$. Tratase de uma obra visionária e proto-vanguardista que uniu as áreas da gravação, da pintura e da poesia num tempo em que, como nota Manuel Portela, a industrialização do livro se começava a afirmar.

À semelhança das duas exposições, decorreu durante todo o ciclo o projecto "Rádio Blake: Versões de William Blake". A colaboração entre o TAGV e a Rádio Universidade de Coimbra fez a montagem e difusão de um conjunto de traduções de poemas de William Blake e de composições musicais baseadas na sua obra. Este projecto permitiu aos ouvintes não só ficarem a conhecer versões vivas dos poemas, como também perceberem a qualidade atemporal e verdadeiramente inspiradora da obra de Blake, visivel nas mais ou menos improváveis apropriações criativas de músicos do século XX, entre eles, Billy Bragg, Bob Dylan, Patti Smith, Van Morrison ou os Doors.

Do que foi dito até aqui e do que se segue fica a ideia de "colaboração" como a palavra-chave deste ciclo. Se observarmos atentamente o programa de Blake no TAGV percebemos desde logo que ele testemunha uma aposta na criação, colaboração e co-produção com companhias artísticas locais. Esta é a intenção deliberadamente assumida pela actual direcção do TAGV, a sua linha orientadora, apesar das reais dificuldades financeiras que o Teatro atravessa. Em certa medida, estas dificuldades devem-se ao não reconhecimento público do 

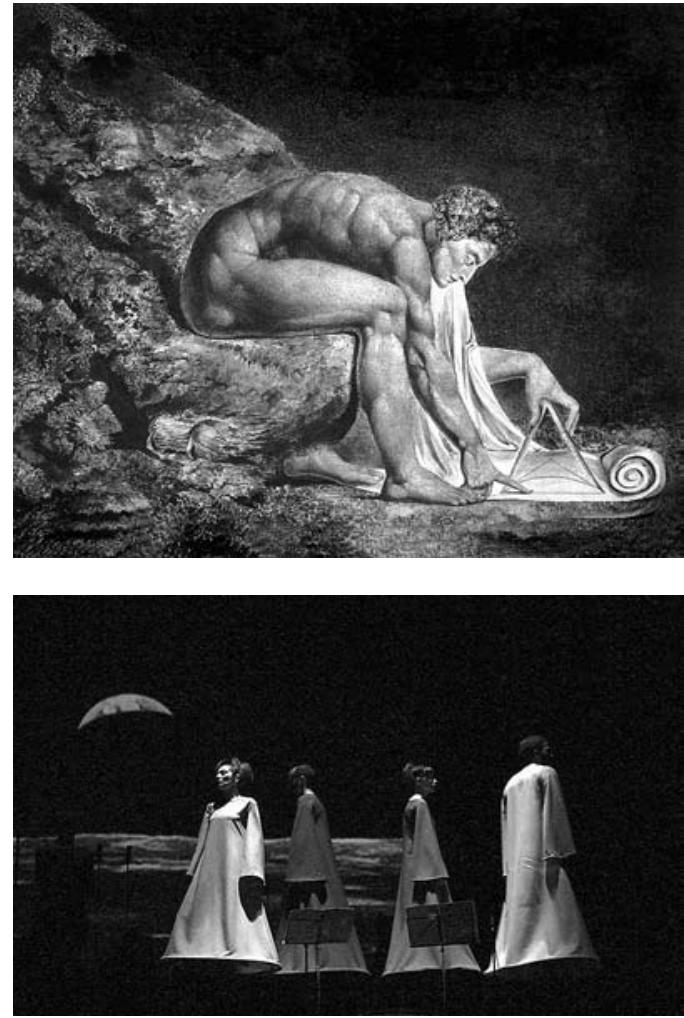

TAGV como aquilo que ele é, ou deveria ser sempre, "um instrumento de uma política artística estruturada para Coimbra"2.

No âmbito deste ciclo foram estreadas duas coproduções do TAGV: Uma ilha na lua, pela companhia Camaleão e com a colaboração da Orquestra Clássica do Centro, e ainda o espectáculo As portas da percepção, pela Marionet. Uma ilha na lua, com direcção artística de José Geraldo e música composta de raiz por Joaquim Pavão para orquestra, soprano, baixo e narradores, parte do texto homónimo de William Blake, escrito em 1784. Este texto é uma obra inacabada, constituída por um conjunto de diálogos e canções satíricas, sem um nexo óbvio, o que torna a transposição para palco uma tarefa difícil, que a Camaleão soube, porém, contornar com engenho. Em vez de tentar disfarçar este carácter fragmentado do texto (utilizado na integra, em tradução de Manuel Portela), José Geraldo opta por exacerbar esse aspecto, apostando na forte demarcação operada pela música de Joaquim Pavão. A música vai progressivamente ocupando um lugar de maior destaque dentro da peça (três andamentos musicais, com 19 canções e narração), suplementando o texto dramático. Não é contudo certo que esta "solução" tenha ajudado à dinâmica do espectáculo, uma vez que para o final da peça os diálogos são constantemente interrompidos por canções e o canto não deixava perceber as letras que também eram paródias, que assim se perderam.

A paródia e a ironia são dois recursos muito caros a Blake. Em Uma ilha na lua o poeta tematiza os códigos sociais para, através das conversas de um grupo singular de habitantes de uma ilha na lua, cujos nomes alegóricos tipificam as personagens (Cínico, Pitagórico, Gás Inflamável, etc.), pôr em cena, por vezes de forma absurda, um conjunto de práticas artísticas, educativas, religiosas e científicas do seu tempo. Na encenação da companhia Camaleão,
Newton,

impressão planográfica a cores sobre papel, com acabamento a tinta e aguarela, $45 \times 60 \mathrm{~cm}$, William Blake, 1795, c. $1805, \odot$ Tate Gallery. esta crítica "aos costumes" não desaparece e a presença e versatilidade dos actores conseguiram, pela simples leitura pública, tornar o texto ainda mais divertido do que ele é em papel, exponenciando o carácter satírico original.

A encenação de Uma ilha na lua aposta na simplicidade que perpassa toda a obra; está presente no cenário (apenas algumas cadeiras), no vídeo (a imagem do planeta Terra) e no próprio grupo de actores (um narrador e quatro actores fixos que interpretam cada uma das personagens, desdobrando-se e multiplicando-se apenas através da mudança de voz). Esta simplicidade não impediu a criação de momentos visualmente poderosos, como quando os actores dançam em cima das cadeiras com vestes longas e coloridas a ondular, solução que transformou a palavra de Blake num verdadeiro corpo presente.

0 outro espectáculo, intitulado As portas da percepção, com direcção artística de Mário Montenegro, foi também um trabalho assente na fragmentação. Não porque se baseasse numa obra inacabada, como sucedia no caso anterior, mas porque parte de uma colagem de excertos de sete livros de William Blake: 0 casamento do céu e do inferno (1790), O livro de Thel (1789), O [primeiro] livro de Urizen (1794), A canção de Los (1795), O livro de Ahania (1795), Visões das filhas de Albion (1793) e Cantigas da inocência e da experiência (1794). 0 prólogo é composto por uma "Visão memorável" da tipografia infernal e o epilogo integra o poema "A rosa doente". Entre um e outro momento vemos as cenas com Thel, Urizen e Los,

Enitharmon e Orc, Ahania e, por último, Oothoon, Bromion e Theotormon. Este espectáculo contrasta ainda com o anterior pela diferença de humor que supõe. 0 tom de paródia é abandonado para entrarmos nos obscuros recantos da poesia de Blake, na sua mitologia própria, onde a paixão pela descoberta ocupa lugar central. É possivel ver neste espectáculo e na escolha dos textos que o compõem o brilho do projecto maior que o poeta pretendeu
Uma ilha na lua, de William Blake, enc. José Geraldo, TAGV, 2007, (Helena Faria, Pedro Malacas, Filipa Freitas, António Mortágua), fot. Francisca Moreira. 


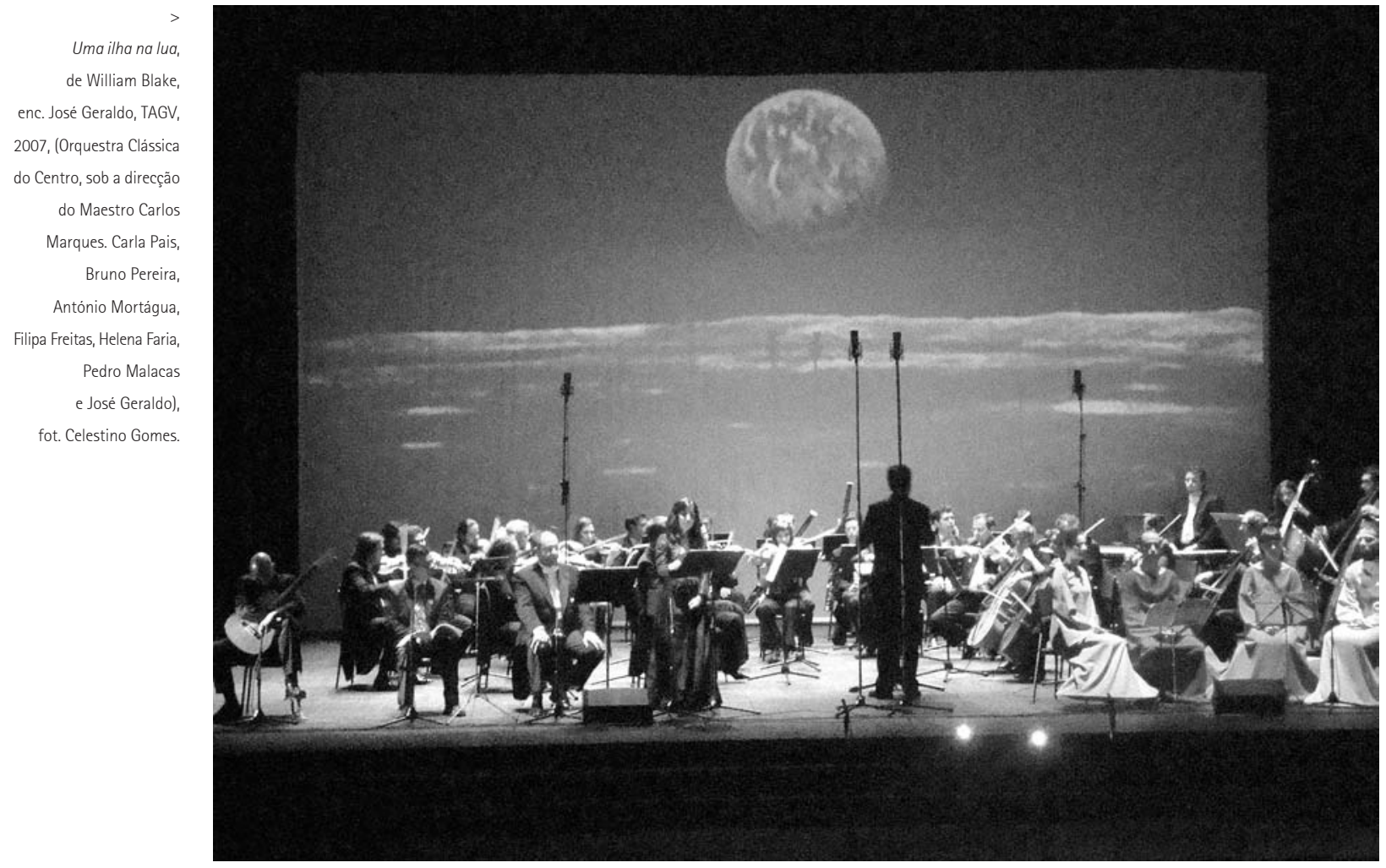

levar a cabo; um projecto de ordem gnoseológica, segundo o qual a arte surgiria como expressão e função vital, enquanto técnica de conhecimento.

0 corpo é para Blake lugar de conhecimento. A expressão "as portas da percepção", que aparece n'0 casamento do céu e do inferno, refere-se precisamente ao enquadramento sensorial do corpo como mediador do que se pode conhecer. Neste espectáculo revela-se muito bela e intensa a imagem do corpo, a sua característica mais marcante é mediada, tal como nas gravuras de Blake, pela energia luminosa proveniente dos músculos, demarcados pelas posturas dos actores. 0 corpo blakiano mostra-se aqui luminescente, gerando luz própria como as estrelas. Louvando a leitura corporal que os actores fazem dos textos, como nota Manuel Portela, o seu trabalho pode/deve ser visto em confronto com as gravuras de Blake:

\footnotetext{
[A]s imagens das gravuras de William Blake são incorporadas nas marcações e posturas cénicas assumidas: em cada um dos quadros da peça há posições e movimentos dos actores que são recriações das gravuras (por exemplo, nas posições corporais de Thel, de Urizen de Los, de Theotormon, das filhas de Albion, etc.), como se um determinado momento da peça pudesse ser parado e transformado numa das imagens dos livros, ou como se imagens dos livros pudessem ganhar movimento e dar a ver, sobre o palco, a sequência de movimentos anterior ou posterior àquela que a gravura fixou. ${ }^{3}$
}

Infelizmente esta força performativa do corpo não encontra igual correspondência nas restantes vertentes do espectáculo. Em toda a obra, sente-se um duelo entre o demasiado explícito e a pura abstracção. Assim, as portas atafulhadas de livros, de ecrãs de televisão e computadores que dominam o cenário estão lá para nos lembrar o óbvio, que isto medeia aquilo que podemos conhecer. Os vídeos oscilaram entre a simples denotação (um campo verdejante ondulando ao vento) e a completa abstracção (rectângulos sobrepostos). Quanto aos actores, para lá do que foi dito em relação à excelente expressão corporal, a forma como diziam o texto, que em si é já bastante longo e difícil, tornou-o algo pesado, dificultando a criação de imagens mentais pelo espectador. É portanto uma proposta irresoluta, mas assinale-se a importância e o significado d'As portas da percepção enquanto tentativa de revisitar a própria percepção da fecunda poesia de Blake.

Todos estes espectáculos e exposições, assim como o ciclo de cinema CineBlake, mostraram como a obra de William Blake pode ser hoje objecto privilegiado da ressignificação que caracteriza os procedimentos das mais diversas áreas e suportes artísticos. Foi também este, de algum modo, o tema da segunda mesa redonda Blakeana 2: Blake Poeta que contou com a participação de Gastão Cruz e Manuel Portela, dois tradutores de mérito da obra de Blake. De Manuel Portela destaca-se ainda o lançamento por esta altura da fabulosa edição bilingue e ilustrada de Cantigas da inocência e da experiência. 0 subtítulo desta obra, "mostrando os dois estados contrários da alma humana", pode bem ficar como mote para o que foi este ciclo: uma viagem magnífica pela linguagem e pela figuração obscura de um poeta à (re)descoberta da secreta verdade dos seres. 